Western University Scholarship@Western

$3-2018$

\title{
The Incidence and Characteristics of Stroke in Urban-Dwelling Iranian Women
}

Amin Amiri MD

Mashhad University of Medical Sciences

Moira Kapral MD MSc

University of Toronto

Amanda G. Thrift PhD

Monash University, Australia

Luciano A. Sposato

Western University, luciano.sposato@lhsc.on.ca

Hamidreza Saber MD

Wayne State University

See next page for additional authors

Follow this and additional works at: https://ir.lib.uwo.ca/anatomypub

Part of the Anatomy Commons, and the Cell and Developmental Biology Commons

\section{Citation of this paper:}

Amiri, Amin MD; Kapral, Moira MD MSc; Thrift, Amanda G. PhD; Sposato, Luciano A.; Saber, Hamidreza MD; Behrouz, Reza Do PhD; Erfanian, Mahdiyeh; Farzadfard, Mohammad Taghi MD; Mokhber, Naghmeh MD; and Azarpazhooh, Reza MD, "The Incidence and Characteristics of Stroke in Urban-Dwelling Iranian Women" (2018). Anatomy and Cell Biology Publications. 115.

https://ir.lib.uwo.ca/anatomypub/115 


\section{Authors}

Amin Amiri MD, Moira Kapral MD MSc, Amanda G. Thrift PhD, Luciano A. Sposato, Hamidreza Saber MD, Reza Behrouz Do PhD, Mahdiyeh Erfanian, Mohammad Taghi Farzadfard MD, Naghmeh Mokhber MD, and Reza Azarpazhooh MD 


\section{The Incidence and Characteristics of Stroke in Urban-Dwelling Iranian Women}

Amin Amiri ${ }^{1}$; Moira K. Kapral ${ }^{2,3}$; Amanda G. Thrift ${ }^{4,5}$; Luciano A. Sposato ${ }^{6,7}$; Hamidreza Saber ${ }^{8}$; Reza

Behrouz $^{9}$; Mahdiyeh Erfanian ${ }^{10}$; Mohammad Taghi Farzadfard ${ }^{1}$; Naghmeh Mokhber ${ }^{11,12}$; and Mahmoud Reza Azarpazhooh ${ }^{1,6,13^{*}}$

${ }^{\mathbf{1}}$ Department of Neurology, Ghaem hospital, Mashhad University of Medical Sciences, Mashhad, Iran

${ }^{2}$ Department of Medicine and Institute of Health Policy, Management and Evaluation, University of Toronto, Toronto, Canada

${ }^{3}$ Institute for Clinical Evaluative Sciences and Toronto General Research Institute, Toronto, Canada

${ }^{4}$ Stroke and Ageing Research, School of Clinical Sciences, Monash University, Clayton, Victoria, Australia

${ }^{5}$ Stroke Division, the Florey Institute of Neuroscience and Mental Health, Melbourne, Victoria, Australia

${ }^{6}$ Department of Clinical Neurological Science, University Hospital, London Health Science Center, the University of Western Ontario, ON, Canada

${ }^{7}$ Stroke, Dementia \& Heart Disease Laboratory, Western University, London, ON. Canada

${ }^{8}$ Department of Neurology, Wayne State University School of Medicine, Detroit, MI, USA

${ }^{9}$ Department of Neurology, School of Medicine, University of Texas, Health Science Center, San Antonio, TX, USA 
${ }^{10}$ Department of Statistics, Faculty of Mathematical Sciences, Ferdowsi University of Mashhad

${ }^{11}$ Department of Psychiatry \& Behavioural Neurosciences, Western University, London, ON, Canada

${ }^{12}$ Department of Psychiatry, Mashhad University of Medical Sciences, Mashhad, Iran

${ }^{13}$ Department of Epidemiology and Biostatistics, Western University, London, ON, Canada

Corresponding to: Dr. Mahmoud Reza Azarpazhooh

- Department of Clinical Neurological Sciences, University of Western Ontario, 339

Windermere Road, London, Ontario, Canada; Tel: +1 519 - 663 - 3624; Fax: +1 519 - 663 - 3910.

- $\quad$ Email: reza.azarpazhooh@lhsc.on.ca

Key words: Women, stroke, incidence, mortality, recurrence

Running title: Stroke in women in Iran

Word count: 3790

Number of tables: 4

Number of figures: 2 


\begin{abstract}
:
Background: Population-based data regarding stroke among women are scarce in developing countries. This study was designed to determine whether sex differences exist in stroke incidence, mortality, and recurrence.
\end{abstract}

Methods: The Mashhad Stroke Incidence Study (MSIS) is a population-based cohort study in Iran. For a period of one year, all patients with stroke in three geographical regions in Mashhad were recruited and then followed up for 5 years. Age- and sex-specific crude incidence rates were standardized to the WHO New World Population. Male/female incidence rate ratios were assessed for all age groups and all subtypes of first ever stroke (FES).

Results: The annual crude incidence rate of FES (per 100000 population) was similar in men (144; 95\% CI: 129-160) and women (133; 95\% CI: 119-149). Standardized FES annual incidence rates were 239 (95\% CI: 213-267) for men and 225 (95\% CI 200-253) for women, both greater than in most western countries. There were no significant differences in stroke recurrence or case-fatality between women and men during early and long-term follow up

Conclusion: The similar incidence of stroke between men and women highlights the importance of equally prioritizing adequate preventive strategies for both sexes. The greater relative incidence of stroke in women in Mashhad compared with other countries warrants improvement of primary and secondary stroke prevention. 


\section{Introduction:}

The underlying ethology, incidence, mortality and outcomes of stroke vary substantially between men and women (1). Although age-specific stroke rates are greater in men, women have more absolute numbers of stroke and poorer outcomes than men due to longer life expectancy and higher incidence rates at age $>85$ years $(1,2)$. Stroke may also be more severe in women (3), and with a greater 30-day case fatality (4).

Valid data regarding women stroke are scarce, particularly in the low/middle-income countries. The current study is designed to investigate sex-specific differences in stroke incidence, mortality and recurrence during five-year follow up in Mashhad, Iran.

\section{Methods and patients:}

\section{Population:}

The present study is part of the Mashhad Stroke Incidence Study (MSIS). The methods of the MSIS have been previously described $(5,6)$. Using multiple overlapping sources all individuals with an acute stroke including ischemic stroke (IS), intracerebral hemorrhage (ICH), subarachnoid hemorrhage (SAH), and undefined stroke (US) and were recruited and followed for 5 years for any changes in health condition (5) (Figure-1; online supplemental data). The study was approved by the Ethics Committee of the Mashhad University of Medical Sciences.

\section{Baseline assessment}

We collected details of clinical history, neurological examinations, neuroimaging information, vascular risk factors and socioeconomic status (education, occupation, household income) for all patients. Specific questions regarding menstruation, pregnancies, use of oral contraceptive pills 
and menopause were also obtained.

\section{Statistical analysis:}

The male/female (M/F) age-adjusted incidence rate ratios were assessed for all age groups and all subtypes of initial stroke. Using the direct method (7) age and sex-specific crude incidence rates were standardized to the WHO New World Population (WHO 2000-2025) standard population. Kaplan-Meier curves were used to compare the cumulative risk of death. Competing risk analysis was used to determine the cumulative incidence of recurrent stroke, with death considered as a competing event for recurrence. Prognostic variables associated with death were assessed using Cox proportional hazard, backward stepwise regression analysis. $\mathrm{P} \leq 0.05$ (two sided) was considered to be statistically significant. $\mathrm{R}$ statistical software was used to run competing risk analysis and cause-specific Cox proportional hazard regression with 95\% CIs. SPSS statistical software (version 16, SPSS Inc., Illinois, and USA) was used for the rest of the statistical analyses. Patients who were not completely followed were included in the competing risk and Kaplan-Meier analyses until they were followed.

\section{Results:}

During the study period, a total of 327 (52.4\%) men and 297 (47.6\%) women with first-ever stroke (FES) were identified. The mean age of stroke was similar between men $(65.0 \pm 14.6)$ and women $(64.1 \pm 15.0 ; \mathrm{p}=0.6)$. Women were more likely than men to have a history of hypertension $(\mathrm{p}<0.001)$, to be single, divorced or widowed $(\mathrm{p}<0.001)$, to be unemployed or a home-maker $(\mathrm{p}<0.001)$ and have an educational level of less than 12 years ( $\mathrm{p}$-value $<0.001)$. Men more often had a history of coronary artery disease, including myocardial infarction $\leq 27$ days $(\mathrm{p}=0.04)$ and $\geq 28$ days before stroke $(\mathrm{p}=0.01)$ than women (Table-1). Despite all attempts, 69 patients were not 
accessible to follow up due to change of address or loss of contact; 3 immediately after discharge from hospital, 5 during the first year and 61 patients after first year (Table-1: online supplemental data).

\section{Incidence:}

The age-specific crude annual incidence rates of stroke are shown in the table 2. The incidence of FES increased similarly in both sexes with each decade of life, with a significant rise after the age 45. There were no differences in overall standardized FES incidence rates between men $(239,95 \%$ CI: 213-267) and women (225, 95\% CI: 200-253) either. Similarly, no sex differences were found for any age group. The total M/F incidence ratio was 1.06 (95\% CI: 0.9-1).

\section{Stroke Subtypes}

The total male/female incidence rate ratios were similar across all types of stroke (Table-3). Ageadjusted incidence rate of ICH among women $<45$ years were almost 3.5 fold higher than men in same age group (F/M ratio: 3.5; 95\% CI: 1-11). No significant differences were observed across all subtypes of IS (Table-2; online supplemental data).

\section{Stroke Recurrence}

Women and men had similar rate of recurrent stroke either at one year (women: $5.4 \%$ vs men: $5.5 \%, \log \operatorname{rank} \mathrm{P}=0.7$ ) and five years after index stroke (men: $13.2 \%$ vs women: $13 \%, \log$ rank $\mathrm{P}=0.7$ ) (Figure-1). Multivariate cox proportional hazard model revealed that only the National Institutes of Health Stroke Scale (NIHSS; HR: 1.05, 95\% CI: 1.01-1.09) and age (HR: 1.03, 95\% CI: 1.01-1.04) were significantly associated with five-year recurrence rate for men. 


\section{Case fatality}

Case fatality was similar in women and men at 30 days (women: $20.4 \%$ vs men: $21.2 \%$ ), one year (women: $31.3 \%$ vs men: $35.5 \%$ ) and five years (women: $53.8 \%$ vs men: $60.5 \%$ ) with no statistically significant differences (Log-rank P: 0.1) (Figure-2). Stroke itself was the most common reason for death in both women $(43.2 \%)$ and men $(39.7 \%$; $=0.9)$.

In univariable Cox proportional hazard regression, increasing age, NIHSS at admission, history of atrial fibrillation and having less than 12 years of education were associated with an increased 5year risk of death for both sexes (Table-4). Furthermore, other sex-specific factors increasing risk of five-year death among men and women are also shown in table 4.

The multivariable Cox proportional hazard model evidenced that advanced age (men: HR: 1.03, 95\% CI: 1.02-1.04; women: HR: 1.03, 95\% CI: 1.02-1.05) and NIHSS (men: HR: 1.11, 95\% CI: 1.09-1.12; women: HR: $1.12,95 \%$ CI: 1.1-1.14) were significantly increased the risk of death during five-year after FES in both men and women. Furthermore, a history of hypertension (HR: 1.5, 95\% CI: 1.1-2.1) was also significantly associated with increased five-year case fatality for men. Among women, a history of atrial fibrillation (HR: 2.04, 95\% CI: 1.3-3.2), current smoking (HR: 1.8, 95\% CI: 1.1-3) and having less than 12 years of education (HR: 7.3, 95\% CI: 1.7-30.9) were significant predictors of five-year case fatality.

\section{Discussion}

Our study has important implications regarding sex-specific differences in stroke epidemiology. In contrast to many studies, the annual incidence rate of FES, the mean age at stroke onset and long-term risk of recurrent stroke and mortality were similar in our male and female subjects. In addition, the level of education had a significant effect on the mortality rate among women. 
Stroke incidence and mortality vary significantly between men and women. As compared to some high-income countries (8-10), we observed higher age-adjusted incidence rates of FES for both sexes in the MSIS. This finding can be probably due to a relatively younger age distribution in Mashhad (5). In many studies, stroke reported more frequently in men (about 33\%) than women (4). Such differences can be partially explained by an overall longer life expectancy among women (11). In our study, although the annual incidence rate of FES among men was $6 \%$ higher than women, this figure did not reach a significant value. This is an important finding, highlighting a greater burden of stroke among women in the MSIS. In addition, the age of stroke also varied in men and women. In a systematic review, the mean age of stroke among women and men were 72.9 years and 68.6 years, respectively (4). We found that a relatively younger age for stroke occurrence, with a similar mean age at stroke onset among women and men (at $\sim 65$ years). Having added this finding to a relatively higher rate of stroke in women in our population indicates a dramatically higher burden of women stroke, emphasizing a target oriented plan to control stroke in women.

To assess the possible reasons of the higher incidence rate of women strokes, we reviewed vascular and demographic risk factor, stratifying subjects according to their age and menopausal status. In total, hypertension was more frequently observed in women than men. In addition, socioeconomic status was also different, with a higher rate of unemployment and low educational level ( $<12$ years) in women. These findings may partially explain our significant difference with many studies which needs long-term public plans to fight against stroke in women.

Studies regarding stroke etiology according to sex are also scarce. Some studies showed higher incidence rates of ICH and IS among men than those in women $(3,4,9)$. Such differences might be explained by the difference in the frequency of vascular risk factors (i.e. smoking, addiction 
and alcohol overuse among men) (3). In contrast, despite the presence of different vascular risk factors, our women and men had similar incidence rates across all subtypes of stroke. However, among patients with $\mathrm{ICH}$, women $<45$ had significantly a higher incidence of stroke (3.5 fold) compared to men at similar age groups. Inconsistent with previous reports $(4,12)$, SAH was more common among men in Mashhad; however, due to relatively low sample size in SAH, this finding should be taken into account with cautions.

We did not find a significant difference in the overall mortality and recurrence rates of stroke among men and women. A systematic review showed that the 30-day case fatality of stroke was 1.25 fold greater in women than men (4) which could be attributable to higher mean age of women than men at time of first stroke. The lack of difference in case fatality in our study, might be due to the age distribution of stroke in men and women in our population. In the MSIS, education less than 12 years was also an independent predictor of five-year death in women. In the Framingham study, the highest stroke case fatality for men and women was attributed to SAH and ICH (13). A similar pattern was observed in our study with the highest 30-day cumulative rate of death in SAH (for men) and ICH (for women). Women had a higher incidence of ICH at younger ages and died more commonly than men due to ICH within 30-day after the index stroke. This might be explained by a larger prevalence of hypertension in our women than men.

There are some limitation which may affect our results. We were not able to completely follow up eleven percent of patients during five-year period of study. Among these patients, both male and female were significantly younger and had lesser severity of stroke than those who were followed up. So their inclusion may have somewhat modified the risk factors independently associated with the risk of recurrence and death for men and women if any of these people had a recurrent event or died. 
To control any source of bias in data collection at baseline and follow up period for men and women, we reviewed the frequency of patients admitted in hospitals versus those who solely managed in the community and also any differences in basic characteristic among those with and without complete follow up time. Hospital admission rates were similar between both sexes (62.4\% of men and $64.6 \%$ women). Therefore, we believe that we were able to capture all men and women with stroke accurately. Finally, an almost door- to -door survey with the help of about 1000 volunteers provided a detailed information about any possible stroke in the study area. Dropout rates during follow up period were similar between men and women. In addition, the list of missing variables, those who lost to follow and those without imaging (undefined strokes) were not significantly different between both sexes.

In summary, a relatively high incidence of stroke among women with a higher rate of death in less educated patients warrant a thorough prevention methods not only to control risk factors but also to improve public health general knowledge. Furthermore, as women tend to live longer, according to the higher life expectancy in Iran (male/female: 74/77), the fact that there is no difference in the age of onset of stroke, is another disadvantage for women which will live longer with their disability.

\title{
Acknowledgment:
}

We appreciate our patients and their family for their active and truly cooperation during five-year follow up.

Source of funding: This research was funded by the Mashhad University of Medical Sciences.

\author{
Disclosure: None
}

Conflict of interest: The author/s declare no conflicts of interest 


\section{References:}

1. Persky RW, Turtzo LC, McCullough LD. Stroke in women: disparities and outcomes. Current cardiology reports. 2010; 12:6-13.

2. Reeves MJ, Bushnell CD, Howard G, Gargano JW, Duncan PW, Lynch G, et al. Sex differences in stroke: epidemiology, clinical presentation, medical care, and outcomes. The Lancet Neurology. 2008; 7:915-26.

3. Roquer J, Campello AR, Gomis M. Sex differences in first-ever acute stroke. Stroke. 2003; $34: 1581-5$.

4. Appelros P, Stegmayr B, Terént A. Sex differences in stroke epidemiology: a systematic review. Stroke. 2009 Apr 10; 40: 1082-90.

5. Azarpazhooh MR, Etemadi MM, Donnan GA, Mokhber N, Majdi MR, Ghayour-Mobarhan M, et al. Excessive incidence of stroke in Iran: evidence from the Mashhad Stroke Incidence Study (MSIS), a population-based study of stroke in the Middle East. Stroke. 2010; 41:e310.

6. Saber H, Thrift AG, Kapral MK, Shoamanesh A, Amiri A, Farzadfard MT, et al. Incidence, recurrence, and long-term survival of ischemic stroke subtypes: A population-based study in the Middle East. International journal of stroke: official journal of the International Stroke Society. 2016 01:1747493016684843.

7. Ahmad OB B-PC, Lopez AD, Murray CJL, Lozano L, Inoue M. Age standardization of rates. A new WHO standard. World Health Organization. http://www.who.int/healthinfo/paper31.pdf. Accessed July 23, 2016.

8. Anderson CS, Jamrozik KD, Burvill PW, Chakera TM, Johnson GA, Stewart-Wynne EG. Determining the incidence of different subtypes of stroke: results from the Perth Community 
Stroke Study, 1989-1990. The Medical journal of Australia. 1993; 158:85-9.

9. Thrift AG, Dewey HM, Sturm JW, Srikanth VK, Gilligan AK, Gall SL, et al. Incidence of stroke subtypes in the North East Melbourne Stroke Incidence Study (NEMESIS):

differences between men and women. Neuroepidemiology. 2009; 32: 11-8.

10. Bahit MC, Coppola ML, Riccio PM, Cipriano LE, Roth GA, Lopes RD, et al. First-Ever Stroke and Transient Ischemic Attack Incidence and 30-Day Case-Fatality Rates in a Population-Based Study in Argentina. Stroke. 2016; 47: 1640-2.

11. Petrea RE, Beiser AS, Seshadri S, Kelly-Hayes M, Kase CS, Wolf PA. Gender differences in stroke incidence and poststroke disability in the Framingham heart study. Stroke. 2009; 40: $1032-7$.

12. Truelsen T, Piechowski-Jóźwiak B, Bonita R, Mathers C, Bogousslavsky J, Boysen G. Stroke incidence and prevalence in Europe: a review of available data. European journal of neurology. 2006; 13: 581-98.

13. Sacco RL, Wolf PA, Kannel WB, McNamara PM. Survival and recurrence following stroke. The Framingham study. Stroke; a journal of cerebral circulation. 1982; 13: 290-5. 

Table 1. Characteristics of the Mashhad stroke incidence Study cohort by sex.

\begin{tabular}{|c|c|c|c|}
\hline Variable & $\begin{array}{l}\text { Male } \\
\mathrm{N}(\%)\end{array}$ & $\begin{array}{l}\text { Female } \\
\mathrm{N}(\%)\end{array}$ & $P$ value \\
\hline Age $($ mean $\pm \mathrm{SD})$ & $64.99 \pm 14.6$ & $64.11 \pm 15.03$ & \multirow{6}{*}{$<0.001$} \\
\hline Hypertension & $165(50.9)$ & $208(70.3)$ & \\
\hline History of Transient Ischemic Attack & $26(8)$ & $23(7.7)$ & \\
\hline Diabetes & $98(30.2)$ & $89(30)$ & \\
\hline Hyperlipidemia & $70(21.7)$ & $78(26.6)$ & \\
\hline Atrial fibrillation & $24(7.6)$ & $28(9.7)$ & \\
\hline $\begin{array}{l}\text { History of acute myocardial infarction } \leq 27 \\
\text { days before stroke }\end{array}$ & $9(2.8)$ & $2(0.7)$ & 0.04 \\
\hline $\begin{array}{l}\text { History of acute myocardial infarction } \geq 28 \\
\text { days before stroke }\end{array}$ & $39(11.9)$ & $18(6.1)$ & \multirow[t]{2}{*}{0.01} \\
\hline History of Dementia & $14(4.3)$ & $9(3)$ & \\
\hline Current smoker & $61(18.7)$ & $37(12.5)$ & 0.03 \\
\hline Ex-smoker & 66 & 32 & 0.001 \\
\hline Addiction & $54(16.5)$ & $24(8.1)$ & 0.001 \\
\hline Alcohol (daily drinker) & $18(5.6)$ & 0 & $<0.001$ \\
\hline Family history of stroke & $54(16.5)$ & $58(19.5)$ & \multirow{6}{*}{$<0.001$} \\
\hline Married & $284(87.7)$ & $180(61.2)$ & \\
\hline Household income & & & \\
\hline Low & $165(50.5)$ & $171(57.6)$ & \\
\hline Medium & $132(40.4)$ & $106(35.7)$ & \\
\hline High & $30(9.2)$ & $20(6.7)$ & \\
\hline \multicolumn{4}{|l|}{ Patient`s occupation } \\
\hline Work pre stroke & $178(58.4)$ & $14(4.8)$ & \multirow{4}{*}{$<0.001$} \\
\hline Retired & $86(26.5)$ & $5(1.7)$ & \\
\hline Disabled & $7(2.2)$ & $2(0.7)$ & \\
\hline Unemployed or home maker & $54(16.6)$ & $270(92.8)$ & \\
\hline \multicolumn{4}{|l|}{ Education } \\
\hline$\leq 12$ years & $233(71.7)$ & $261(90)$ & \multirow{3}{*}{$<0.001$} \\
\hline$\geq 13$ years & $92(28.3)$ & $29(10)$ & \\
\hline NIHSS at admission & $10.9 \pm 10.34$ & $10.7 \pm 10.2$ & \\
\hline
\end{tabular}

*Abbreviation (in alphabetic order): National institutes of health stroke scale (NIHSS) 
Table 2. The age and sex specific and WHO age-adjusted incidence rates of first-ever stroke in Mashhad, Iran.

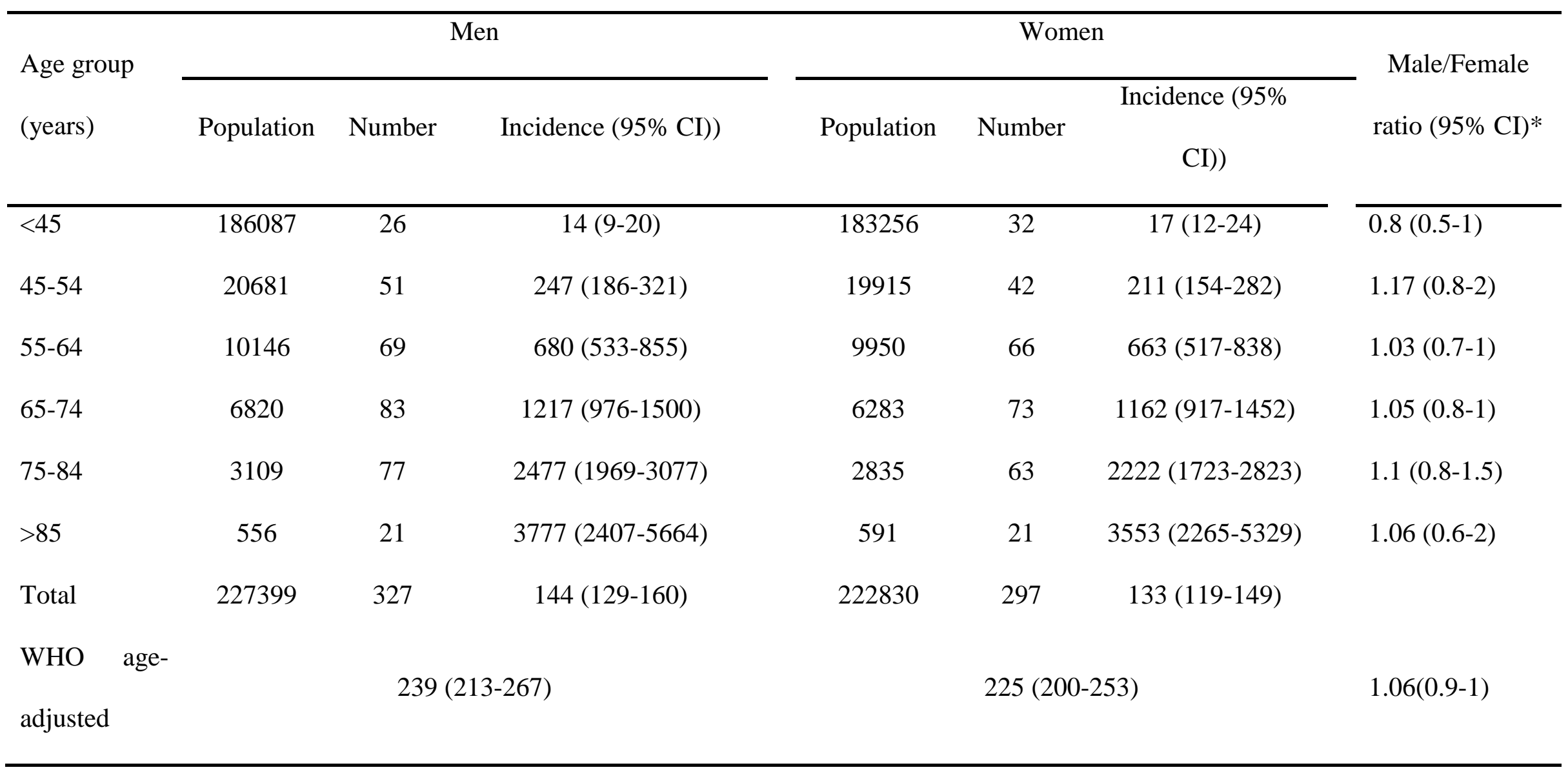

*Male/Female age-adjusted incidence rate ratio; CI, Confidence Interval; WHO, World Health Organization; Incidence is per 100,000 population per year. 
Table 3. The age and sex specific incidence rates per 100000 along with the male-female incidence ratio for all subtypes of first ever stroke.

\begin{tabular}{|c|c|c|c|c|c|c|c|c|c|c|}
\hline \multirow{3}{*}{$\begin{array}{l}\text { Age } \\
\text { groups }\end{array}$} & \multicolumn{5}{|c|}{ Ischemic Stroke } & \multicolumn{5}{|c|}{ Intracerebral Hemorrhage } \\
\hline & \multicolumn{2}{|c|}{ Male } & \multicolumn{2}{|c|}{ Female } & \multirow{2}{*}{$\begin{array}{c}\text { Male/Female } \\
\text { ratio } \\
(95 \% \mathrm{CI})^{*}\end{array}$} & \multicolumn{2}{|c|}{ Male } & \multicolumn{2}{|c|}{ Female } & \multirow{2}{*}{$\begin{array}{c}\text { Male/Female } \\
\text { ratio } \\
(95 \% \mathrm{CI})^{*}\end{array}$} \\
\hline & Number & $\begin{array}{c}\text { Incidence } \\
\text { rate }\end{array}$ & Number & $\begin{array}{l}\text { Incidence } \\
\text { rate }\end{array}$ & & Number & $\begin{array}{l}\text { Incidence } \\
\text { rate }\end{array}$ & Number & $\begin{array}{c}\text { Incidence } \\
\text { rate }\end{array}$ & \\
\hline$<45$ & 19 & 10 & 22 & 12 & $0.9(0.5-2)$ & 2 & 1.1 & 7 & 3.8 & $0.3(0.06-2)$ \\
\hline$\geq 45$ & 245 & 593 & 226 & 571 & $1.03(0.9-1)$ & 43 & 104 & 28 & 70.7 & $1.5(1.02-2)$ \\
\hline Total & 264 & 116.1 & 248 & 111.3 & & 45 & 19.7 & 35 & 15.7 & \\
\hline $\begin{array}{l}\text { WHO age- } \\
\text { adjusted }\end{array}$ & \multicolumn{2}{|c|}{$172(152-195)$} & \multicolumn{2}{|c|}{$168(147-190)$} & $1.02(0.9-1)$ & \multicolumn{2}{|c|}{$30(22-40)$} & \multicolumn{2}{|c|}{$22(15-31)$} & $1.3(0.9-2)$ \\
\hline
\end{tabular}

Table 3 continued:

\begin{tabular}{|c|c|c|c|c|c|c|c|c|c|c|}
\hline \multirow{3}{*}{$\begin{array}{c}\text { Age } \\
\text { groups }\end{array}$} & \multicolumn{5}{|c|}{ Subarachnoid Hemorrhage } & \multicolumn{5}{|c|}{ Undefined Stroke } \\
\hline & \multicolumn{2}{|c|}{ Male } & \multicolumn{2}{|c|}{ Female } & \multirow{2}{*}{$\begin{array}{c}\text { Male/Female } \\
\text { ratio } \\
(95 \% \mathrm{CI})^{*}\end{array}$} & \multicolumn{2}{|c|}{ Male } & \multicolumn{2}{|c|}{ Female } & \multirow{2}{*}{$\begin{array}{c}\text { Male/Female } \\
\text { ratio } \\
(95 \% \mathrm{CI})^{*}\end{array}$} \\
\hline & Number & $\begin{array}{c}\text { Incidence } \\
\text { rate }\end{array}$ & Number & $\begin{array}{c}\text { Incidence } \\
\text { rate }\end{array}$ & & Number & $\begin{array}{c}\text { Incidence } \\
\text { rate }\end{array}$ & Number & $\begin{array}{c}\text { Incidence } \\
\text { rate }\end{array}$ & \\
\hline$<45$ & 3 & 1.6 & 2 & 1.1 & $1.5(0.4-7)$ & 2 & 1.1 & 1 & 0.5 & $2(0.5-13)$ \\
\hline$\geq 45$ & 5 & 12.1 & 4 & 10.1 & $1.2(0.5-3)$ & 8 & 19.4 & 7 & 17.7 & $1.1(0.5-3)$ \\
\hline Total & 8 & 3.5 & 6 & 2.7 & & 10 & 4.4 & 8 & 3.6 & \\
\hline $\begin{array}{l}\text { WHO age- } \\
\text { adjusted }\end{array}$ & 4.5 & $(2-9)$ & & $1-8)$ & $1.3(0.5-3)$ & & $-11)$ & $5(2-11)$ & & $1.2(0.6-3)$ \\
\hline
\end{tabular}


Table 4: Univariable analysis of risk factors for mortality during five years after first ever stroke using Cox proportional hazards regression.

\begin{tabular}{|c|c|c|c|c|c|c|}
\hline \multirow{4}{*}{ Variable } & \multicolumn{3}{|c|}{ Male } & \multicolumn{3}{|c|}{ Female } \\
\hline & \multicolumn{2}{|c|}{ Five-year death } & \multirow[t]{3}{*}{$\begin{array}{l}\text { Hazard ratio } \\
(95 \% \mathrm{CI})\end{array}$} & \multicolumn{2}{|c|}{ Five-year death } & \multirow[t]{3}{*}{$\begin{array}{l}\text { Hazard ratio } \\
(95 \% \mathrm{CI})\end{array}$} \\
\hline & Yes & No & & Yes & No & \\
\hline & $\mathrm{N}(\%)$ & $\mathrm{N}(\%)$ & & $\mathrm{N}(\%)$ & $\mathrm{N}(\%)$ & \\
\hline Age (mean \pm SD) & $69+13.3$ & $59.8+14.7$ & $1.03(1.01-1.04)$ & $70.4+13.7$ & $57.8+13.7$ & $1.04(1.03-1.06)$ \\
\hline NIHSS at admission (mean \pm SD) & $14.3+11.4$ & $4.7+5.1$ & $1.09(1.07-1.1)$ & $14.9+11.5$ & $5.2+5.6$ & $1.1(1.08-1.1)$ \\
\hline History of TIA before index stroke & $17(9.2)$ & $9(6.3)$ & $1.4(0.8-2.3)$ & $12(8.2)$ & $11(7.4)$ & $1.2(0.7-2.2)$ \\
\hline Diabetes mellitus & $60(32.6)$ & $37(26.1)$ & $1.07(0.8-1.4)$ & $39(26.7)$ & $48(32.2)$ & $0.8(0.6-1.2)$ \\
\hline Hypertension & $111(60.3)$ & $53(37.3)$ & $1.7(1.3-2.3)$ & $103(70.5)$ & $104(69.8)$ & $1.03(0.7-1.5)$ \\
\hline Atrial fibrillation & $20(10.9)$ & $4(2.8)$ & $2.3(1.4-3.6)$ & $21(14.4)$ & $7(4.7)$ & $2.4(1.5-3.7)$ \\
\hline Hyperlipidemia & $44(23.9)$ & $26(18.3)$ & $1.1(0.8-1.6)$ & $33(22.6)$ & $45(30.2)$ & $0.7(0.5-1.1)$ \\
\hline Current smoker & $26(14.1)$ & $35(24.6)$ & $1.7(1.1-2.6)$ & $18(12.3)$ & $18(12.1)$ & $0.9(0.6-1.6)$ \\
\hline Current alcohol drinker & $6(33)$. & $12(8.5)$ & $0.5(0.2-1.01)$ & 0 & 0 & \\
\hline Persian ethnicity & $152(82.6)$ & $126(88.7)$ & $0.7(0.5-1.04)$ & $122(83.6)$ & $118(79.2)$ & $1.2(0.8-1.9)$ \\
\hline \multicolumn{7}{|l|}{ Index stroke } \\
\hline Intracerebral hemorrhage & $29(15.8)$ & $16(11.3)$ & $1.3(0.5-3.1)$ & $20(13.7)$ & $15(10.1)$ & $1.9(0.6-6.5)$ \\
\hline Ischemic stroke & $145(78.8)$ & $118(83.1)$ & $0.8(0.3-1.7)$ & $123(84.2)$ & $123(82.6)$ & $1.4(0.5-4.5)$ \\
\hline Subarachnoid hemorrhage & $4(2.2)$ & $4(2.8)$ & $0.8(0.2-2.7)$ & 0 & $6(4)$ & \\
\hline
\end{tabular}




\begin{tabular}{|c|c|c|c|c|c|c|}
\hline \multicolumn{7}{|l|}{ Income } \\
\hline Low annual income $(<\$$ US 2580) & $98(53.3)$ & $66(46.5)$ & $1.1(0.7-1.7)$ & $99(67.8)$ & $70(47)$ & $3(1.2-7.5)$ \\
\hline Middle annual income (\$US $2580-5160$ ) & $67(36.4)$ & $65(45.8)$ & $0.9(0.5-1.4)$ & $42(28.8)$ & $64(43)$ & $1.7(0.7-4.3)$ \\
\hline \multicolumn{7}{|l|}{ Employment status } \\
\hline Retired & $52(28.3)$ & $33(23.2)$ & $1.3(0.9-1.9)$ & $1(0.7)$ & $4(2.7)$ & $0.5(0.1-4)$ \\
\hline Disabled & $4(2.2)$ & $3(2.1)$ & $1.5(0.5-4)$ & $2(1.4)$ & 0 & $4.1(0.9-20)$ \\
\hline Unemployed & $40(21.7)$ & $14(9.9)$ & $1.8(1.2-2.6)$ & $136(93.2)$ & $132(88.6)$ & $1.7(0.8-3.5)$ \\
\hline Educated $<=12$ years & $34(18.5)$ & $60(42.3)$ & $2(1.4-2.9)$ & $10(6.8)$ & $26(17.4)$ & $2.2(1.1-4.2)$ \\
\hline Family history of stroke & $33(17.9)$ & $21(14.8)$ & $1.2(0.8-1.7)$ & $28(19.2)$ & $29(19.5)$ & $1.1(0.7-1.6)$ \\
\hline
\end{tabular}


Figure 1: The cumulative incidence of recurrent stroke accounting for competing risk of death after the index first ever stroke during the 5-year study period among men and women.

Figure 2. Kaplan-Meier curve showing the five-year probability of death among men and women in MSIS. 
